Published in final edited form as:

Am J Cardiol. 2019 June 15; 123(12): 2022-2025. doi:10.1016/j.amjcard.2019.03.030.

\title{
Relation of Patent Foramen Ovale to Acute Mountain Sickness
}

Brian H. West, MDa, Rubine Gevorgyan Fleming, MDa, Bashar Al Hemyari, MD ${ }^{\mathrm{b}}$, Pooya Banankhah, MD ${ }^{c}$, Kenneth Meyer, BA ${ }^{a}$, Leslie H. Rozier, DNPa, Linda S. Murphy, MLIS ${ }^{d}$, Alexandra C. Coluzzi, BS ${ }^{a}$, Joshua L. Rusheen, BS ${ }^{e}$, Preetham Kumar, MD ${ }^{a}$, David Elashoff, PhD ${ }^{a, f, g}$, and Jonathan M. Tobis, MD ${ }^{a}$

aDivision of Cardiology, Department of Medicine, David Geffen School of Medicine at UCLA, Los Angeles, CA

${ }^{b}$ Department of Medicine, University of California, Riverside

'Department of Internal Medicine, David Geffen School of Medicine at UCLA, Los Angeles, CA

dUniversity of California, Irvine Libraries, Reference Department, Irvine, CA

eDavid Geffen School of Medicine at UCLA

fDepartment of Biostatistics, UCLA, Los Angeles, CA

gDepartment of Biomathematics, UCLA, Los Angeles, CA

\section{Abstract}

Over $50 \%$ of people who rapidly ascend to extreme altitudes develop various symptoms known as acute mountain sickness (AMS), which rarely can be life threatening. It is unclear why some people are more susceptible to AMS than others. Our objective was to determine whether patent foramen ovale (PFO) is a risk factor for AMS. Subjects who had hiked to altitudes above 10,000' ( 3,000 meters) on the John Muir Trail in California were recruited. Participants completed a questionnaire and two-physician adjudication was performed in regard to AMS status. A transcranial Doppler with agitated saline contrast injection was performed to evaluate the presence or absence of PFO. The primary outcome was the development of AMS. From 2016 to 2018, 137 hikers were recruited into the study. There was a higher prevalence of PFO in hikers with AMS 15/24 (63\%) compared to hikers without AMS 44/113 (39\%); $p=0.034$. In the multivariate model, the presence of a PFO significantly increased the risk for developing AMS: OR 4.15, 95\% CI $1.14-15.05 ; p=0.030$. In conclusion, hikers with a PFO had significantly higher risk of developing AMS relative to hikers without a PFO. Clinicians should consider PFO a risk factor in people who plan to hike to high altitudes.

Corresponding author: Brian H. West, MD, 650 Charles E. Young Drive South, CHS A2-237, Los Angeles, CA 90095-1679, Phone: 516-319-5752 (c) bwest@ mednet.ucla.edu.

Disclosures: None of the authors have relative relationships with industry to disclose.

Publisher's Disclaimer: This is a PDF file of an unedited manuscript that has been accepted for publication. As a service to our customers we are providing this early version of the manuscript. The manuscript will undergo copyediting, typesetting, and review of the resulting proof before it is published in its final citable form. Please note that during the production process errors may be discovered which could affect the content, and all legal disclaimers that apply to the journal pertain. 


\section{Keywords}

Patent foramen ovale; acute mountain sickness; right-to-left shunt

Over $50 \%$ of people who rapidly ascend to significant altitudes develop Acute Mountain Sickness (AMS) ${ }^{1-4}$. The symptoms, as defined by the Lake Louise Scoring System, include headache, gastrointestinal upset, fatigue, difficulty sleeping, and lightheadedness ${ }^{5,6}$. Up to $25 \%$ of individuals visiting only moderate altitudes, from 6,300 ' to 9,700 ', have become symptomatic ${ }^{7}$. AMS can progress to life threatening conditions such as High-Altitude Pulmonary Edema (HAPE) and High-Altitude Cerebral Edema (HACE) $)^{1,8}$. It is unclear why some people are more susceptible to AMS than others. A history of AMS, the number of days spent at high altitude during the preceding two months, and the rate of ascent are major independent determinants of the incidence of AMS ${ }^{3,9}$. These factors likely contribute to the degree and rate of onset of hypoxemia, which has been proposed to initiate the cascade of events leading to AMS ${ }^{10}$. Patent foramen ovale (PFO) is an embryologic residual right-toleft cardiac shunt found in $18.0 \%-27.3 \%$ of the general population ${ }^{11,12}$. Depending on the severity of the shunt, this can lead to hypoxemia. Previous evidence has implicated PFO in HAPE ${ }^{13}$. In this study, we investigated whether hikers who developed AMS were more likely to have a PFO than hikers who did not develop AMS symptoms.

\section{Methods}

Subjects who had hiked to altitudes above 10,000 ' $(\sim 3,000$ meters) were recruited to this study. The initial group had climbed all or part of the John Muir Trail (JMT) in California. The JMT varies in altitude between 4,000' in Yosemite Valley to 14,500' at the top of Mount Whitney. In 2015, the John Muir Trail Survey Group conducted a self-report analysis of 1,500 hikers ${ }^{14}$. These survey participants were asked to come to UCLA to complete an AMS questionnaire and to undergo a transcranial Doppler (TCD) study.

To increase enrollment, a second method for recruiting subjects was devised. Permission was obtained from the Inyo National Forest Service to recruit hikers along the Mount Whitney Trail during the 2017 and 2018 summers. Recruiters were stationed both at Whitney Portal $\left(8,200^{\prime}\right)$ and at Whitney Trail Camp $\left(12,000^{\prime}\right)$. Hikers were provided information about the study and were consented prior to participating. Volunteers were directed to the Southern Inyo Hospital in Lone Pine, California, at the foot of Mount Whitney. Upon arrival, they completed an AMS questionnaire. This included the original Lake Louise Acute Mountain Sickness Scoring System ${ }^{5}$ as well as questions regarding acclimatization and premedication, and whether climbers had to stop their ascent due to symptoms or if their symptoms were alleviated by descent.

The original Lake Louise Acute Mountain Sickness Scoring System is a self-reported metric that quantitates the degree of discomfort experienced for the following five variables: headache, gastrointestinal symptoms (nausea, vomiting, and/or changes in appetite), fatigue and/or weakness, dizziness and/or lightheadedness, and difficulty sleeping; a total score cutoff for AMS is 3 or higher ${ }^{5}$. This score was revised in 2018 and difficulty sleeping was 
removed and replaced with an AMS functional score representing the impact an individual's symptoms had on their climb ${ }^{6}$.

Each questionnaire was reviewed, and two-physician adjudication was performed in regard to AMS status. The overall Lake Louise Acute Mountain Sickness Score was considered as was functional status. Adjudication was completed prior to PFO testing.

After antecubital sterilization, an intravenous line was inserted into a forearm vein and a TCD study was performed using a portable machine (Spencer technologies, Seattle, WA). TCD is the most sensitive method for determining if an individual has a right-to-left shunt (RLS) when compared with direct probing of the septum during cardiac catheterization ${ }^{15,16}$. This test requires an intravenous injection of $8 \mathrm{~mL}$ agitated saline mixed with $1 \mathrm{~mL}$ of blood and $0.5 \mathrm{~mL}$ of air, while the middle cerebral arteries are assessed with Doppler ultrasound at a frequency of $2 \mathrm{MHz}{ }^{17}$.

Shunts were graded using the Spencer Logarithmic Scale, which counts the number of bubbles detected per minute in the middle cerebral arteries and ranges from 0-5, with 0 denoting the absence of a shunt and 5 denoting the presence of a large shunt (>300 bubbles/ minute $)^{15,18}$. Measurements were taken both at rest and following a Valsalva maneuver. Manometry was used to obtain consistency of Valsalva effort. The cutoff for a positive test is Grade 3, which corresponds to the presence of a PFO at cardiac catheterization ${ }^{15}$.

Although the TCD examination reveals the presence of a RLS, it does not distinguish between a PFO and pulmonary arteriovenous malformation. In our experience of $1500 \mathrm{TCD}$ studies, the rate of pulmonary arteriovenous malformation is only $1 \%$ in patients referred without hereditary hemorrhagic telangiectasia, thus, a positive RLS examination by TCD was used to define the prevalence of PFO ${ }^{19,20}$.

Baseline characteristics were collected and compared between hikers with and without PFO; continuous and categorical variables were compared via t-test and Pearson $\mathcal{\chi}$, respectively. A simple logistic model was created for PFO predicting AMS. Additionally, a multivariate logistic regression model adjusted for age, gender, the use of AMS prophylaxis, and acclimatization was created. AMS prophylaxis included taking medications which can mitigate symptoms of high altitude, such as acetazolamide and/or a non-steroidal antiinflammatory, prior to ascent ${ }^{21,22}$ Participants were considered acclimatized if they spent more than two days at altitude above 8,000 ' prior to attempting the Mount Whitney summit 23.

Lake Louise AMS Scores were compared between hikers who were adjudicated as experiencing AMS versus those who were adjudicated as not having AMS via t-test. Additionally, this comparison was repeated with the categories of "Difficulty Sleeping" and "Fatigue and/or Weakness" removed; these modifications were made to reflect the conditions of hiking up to 22 miles/day to the top of Mount Whitney as well as the change in the Lake Louise AMS Score which occurred while this study was ongoing ${ }^{6}$. TCD Spencer grade was compared between those who developed AMS and those who did not develop AMS via Fisher's exact test. 
This project was approved by the UCLA Institutional Review Board and the Inyo National Forest Ranger Office.

\section{Results}

During the initial recruitment phase as well as during the summers of 2017 and 2018, 137 hikers were recruited into the study. Of these participants, 59 (43\%) hikers were diagnosed with a PFO and $78(57 \%)$ hikers were negative for a PFO. There were no significant baseline differences between these groups [Table 1].

Based on adjudication prior to TCD testing, 24 (18\%) hikers had symptoms consistent with AMS and $113(82 \%)$ hikers did not. There was a higher prevalence of PFO in hikers with AMS 15/24 (63\%) compared to hikers without AMS 44/113 (39\%) [Figure 1]. The presence of a PFO significantly increased the risk for developing AMS: OR 2.61, 95\% CI $1.05-6.49$; $\mathrm{p}=0.038$.

In the multivariate model, when adjusted for age, gender, AMS prophylaxis and acclimatization, the relationship between PFO and AMS became stronger: OR 4.15, 95\% CI $1.14-15.05 ; p=0.030$ ) [Table 2]. None of the other variables in the model were significant predictors for AMS.

Lake Louise AMS Scores were significantly higher in hikers who were adjudicated as having AMS compared to those who were adjudicated as having no AMS, $7.43 \pm 3.04$ versus $2.89 \pm 2.27$, respectively; $\mathrm{p}<0.0001$. When the categories of "Difficulty Sleeping" and "Fatigue and/or Weakness" were removed, the scores remained significantly higher in the hikers who were adjudicated as having AMS compared to those who were adjudicated as having no AMS, $4.67 \pm 1.32$ versus $1.59 \pm 1.49$, respectively; $p<.0001$ ). TCD Spencer grade was significantly higher in those who developed AMS compared to those who did not develop AMS $(\mathrm{p}=0.011)$ [Figure 2].

\section{Discussion}

In our study, hikers with a PFO had significantly higher risk (3x) of developing AMS relative to hikers without a PFO. This relationship was seen in our unadjusted model and was strengthened when we controlled for other variables that have previously been associated with AMS. Clinicians should consider PFO a risk factor in people who plan to hike to high altitudes.

There is prior work to suggest that PFO may play a role in HAPE. In 2006, Allemann et. al. demonstrated that a PFO was 4 to 5 times more likely to be identified in professional mountain climbers who were HAPE-susceptible compared to those who were HAPEresistant. The authors demonstrated that climbers with a PFO developed a greater degree of hypoxemia compared to those without a $\mathrm{PFO}^{13}$. These findings supported a previouslypostulated hypothesis regarding HAPE pathophysiology, the cyclic interplay of hypoxic pulmonary hypertension and right-to-left shunting ${ }^{24}$. 
However, if the development of AMS was solely related to right-to-left shunting, one would expect to see a significant difference in oxygen saturations between those who develop AMS and those who do not, particularly at altitude. We did not find this association but the oxygen saturation was obtained at rest, not during exercise. Additionally, there was a significant portion of participants with PFO in our study who did not develop AMS. It is interesting to note there were a large number of hikers, both with and without AMS, who had a PFO in our study. The prevalence in our population was $43 \%$, which is higher than typical rates seen in other populations ${ }^{11,12}$ The reason for this is unclear.

PFO is associated with a wide variety of clinical conditions, including stroke in young people, migraine headaches with aura, exacerbation of sleep apnea, platypnea-orthodeoxia syndrome, and decompression illness ${ }^{25-28}$. One unifying hypothesis for these associations is that an embolus or biochemical trigger, normally restricted to the venous circulation, enters the systemic circulation to produce these clinical syndromes. This hypothesis would also explain the multi-organ involvement in AMS due to excessive hypoxemia from the RLS.

The JMT and Mount Whitney have become very popular trails even for inexperienced hikers or backpackers. Thousands of hikers with various levels of experience attempt these trails every year ${ }^{29}$ It is possible to climb to the top of Mount Whitney $(14,500$ ') in one day, although the task is daunting with an elevation delta of 6500' and 11 miles in each direction. The Lake Louise AMS Scoring System does not function well for single day hikes. This is due to both the "Difficulty Sleeping" and "Fatigue and/or Weakness" subcategories. Hikers often get only a few hours of sleep before they start out at Whitney Portal between 2 - 4 AM. It is not surprising that many describe poor sleep and excessive fatigue. These are not necessarily due to the hypoxemia of high altitude but to the degree of exertion and lack of conditioning of the hikers.

Due to these considerations, only three sections of The Lake Louise AMS Scoring System were used in the adjudication of AMS. The degree to which each hiker's symptoms impacted their ability to continue climbing, or symptoms that improved upon descent, were also considered. In support of this approach, while this study was ongoing, a new Lake Louise Acute Mountain Sickness Scoring System was released, which replaced the "Difficulty Sleeping" category with a "Clinical Function Score" 6.

One limitation of this study was the self-report questionnaires on symptoms of AMS. To help reduce biases and improve data capture, we reviewed responses with each participant prior to adjudication. However, participant surveys were not always complete. Another limitation of this study was its observational nature and the biases inherent in this design. The association between PFO and AMS does not prove causation; instead, our findings are hypothesis generating. Additional studies are needed to further elucidate the relationship between PFO and AMS. Moreover, a prospective randomized trial of PFO closure versus standard therapy is warranted to determine whether PFO closure could alleviate the symptoms of AMS. 


\section{Acknowledgements}

We would like to thank the UCLA Specialty Training and Advanced Research (STAR) program for support of this project. This project was funded in part by NIH grant 5T32HL007895-19 and we would like to thank Dr. James N. Weiss (PI) for his support. We would like to thank Douglas Thompson of the Mount Whitney Store, Linda Riddle and Rosalie Herrera from the Inyo National Forest Service, Brian Cotter, Maritza Perkins, and the staff of Southern Inyo Hospital, for their support of this project. We extend special appreciation to Sinclair Fleming, Dara West, MD, and Benjamin Hudson West for their help.

Grants, contracts, other financial support:

Brian H. West - NIH grant 5T32HL007895-19; PI: Dr. James N. Weiss

\section{References}

1. Hackett PH, Rennie D, Levine HD. The incidence, importance, and prophylaxis of acute mountain sickness. Lancet 1976;2:1149-1155. [PubMed: 62991]

2. Maggiorini M, Buhler B, Walter M, Oelz O. Prevalence of acute mountain sickness in the Swiss Alps. Bmj 1990;301:853-855. [PubMed: 2282425]

3. Bartsch P, Swenson E. Clinical practice: Acute high-altitude illnesses. The New England journal of medicine 2013;368:2294-2302. [PubMed: 23758234]

4. Johnson T, Rock P. Current concepts. Acute mountain sickness. The New England journal of medicine 1988;319:841-845. [PubMed: 3045554]

5. Roach R, Bartsch P, Hacket P, Oelz O. THE LAKE LOUISE ACUTE MOUNTAIN SICKNESS SCORING SYSTEM. Burlington, VT: Queen City Press 1993.

6. Roach R, Hackett P, Oelz O, Bartsch P, Luks A, MacInnis M, Baillie J. The 2018 Lake Louise Acute Mountain Sickness Score. High Alt Med Biol 2018;19:4-6. [PubMed: 29583031]

7. Honigman B, Theis MK, Koziol-McLain J, Roach R, Yip R, Houston C, Moore LG. Acute mountain sickness in a general tourist population at moderate altitudes. Ann Intern Med 1993;118:587-592. [PubMed: 8452324]

8. Wu T, Ding S, Liu J, Yu M, JH J, Chai Z, Dai R, Zhang S, Li B, Pan L, Liang E Zhao J, Qd T, Sun Y, Kayser B. Who should not go high: chronic disease and work at altitude during construction of the Qinghai-Tibet railroad. High Alt Med Biol 2007;8:88-107. [PubMed: 17584003]

9. Schneider M, Bernasch D, Weymann J, Holle R, Bartsch P. Acute mountain sickness: influence of susceptibility, preexposure, and ascent rate. Med Sci Sports Exerc 2002;34:1886-1891. [PubMed: 12471292]

10. Davis C, Hackett P. Advances in the Prevention and Treatment of High Altitude Illness. Emerg Med Clin North Am 2017;35:241-260. [PubMed: 28411926]

11. Hagen PT, Scholz DG, Edwards WD. Incidence and size of patent foramen ovale during the first 10 decades of life: an autopsy study of 965 normal hearts. Mayo Clin Proc 1984;59:17-20. [PubMed: 6694427]

12. Mojadidi MK, Khessali H, Gevorgyan R, Levinson RD, Tobis JM. Visual migraine aura with or without headache: association with right to left shunt and assessment following transcutaneous closure. Clin Ophthalmol 2012;6:1099-1105. [PubMed: 22888208]

13. Allemann Y, Hutter D, Lipp E, Sartori C, Duplain H, Egli M, Cook S, Scherrer U, Seiler C. Patent foramen ovale and high-altitude pulmonary edema. Jama 2006;296:2954-2958. [PubMed: 17190896]

14. Rozier L, Aksamit I, Meyer K. An Unofficial Acclimatization Guideline for JMT Hikers. https:// unofficialacclimatizationguideline.blogspot.com/p/survey-results.html, 2015.

15. Spencer MP, Moehring MA, Jesurum J, Gray WA, Olsen JV, Reisman M. Power m-mode transcranial Doppler for diagnosis of patent foramen ovale and assessing transcatheter closure. $\mathrm{J}$ Neuroimaging 2004;14:342-349. [PubMed: 15358955]

16. Mojadidi MK, Roberts SC, Winoker JS, Romero J, Goodman-Meza D, Gevorgyan R, Tobis Jonathan M. Accuracy of transcranial Doppler for the diagnosis of intracardiac right-to-left shunt: 
a bivariate meta-analysis of prospective studies. JACC Cardiovascular imaging 2014;7:236-250. [PubMed: 24560213]

17. Purkayastha S, Sorond F. Transcranial Doppler ultrasound: technique and application. Semin Neurol 2012;32:411-420. [PubMed: 23361485]

18. Lao AY, Sharma VK, Tsivgoulis G, Frey JL, Malkoff MD, Navarro JC, Alexandrov AV. Detection of right-to-left shunts: comparison between the International Consensus and Spencer Logarithmic Scale criteria. J Neuroimaging 2008;18:402-406. [PubMed: 18333839]

19. Goutman SA, Katzan IL, Gupta R. Transcranial Doppler with bubble study as a method to detect extracardiac right-to-left shunts in patients with ischemic stroke. J Neuroimaging 2013;23:523525. [PubMed: 22928688]

20. Puledda F, Toscano M, Pieroni A, Veneroso G, Di Piero V, Vicenzini E. Right-to-left shunt detection sensitivity with air-saline and air-succinil gelatin transcranial Doppler. Int J Stroke 2016;11:229-238. [PubMed: 26783315]

21. Pandit A, Karmacharya P, Pathak R, Giri S, Aryal M. Efficacy of NSAIDs for the prevention of acute mountain sickness: a systematic review and meta-analysis. J Community Hosp Intern Med Perspect 2014;4.

22. Basnyat B, JH G, Johnson E, Castro-Marin F, Inoue Y, Yeh C. Efficacy of low-dose acetazolamide (125 mg BID) for the prophylaxis of acute mountain sickness: a prospective, double-blind, randomized, placebo-controlled trial. High Alt Med Biol 2003;4:45-52. [PubMed: 12713711]

23. Hackett PH, Shlim DR. CDC Yellow Book 2018. New York, NY: Oxford University Press, 2017.

24. Levine BD, Grayburn PA, Voyles WF, Voyles WF, Greene ER, Roach RC, Hackett PH. Intracardiac shunting across a patent foramen ovale may exacerbate hypoxemia in high-altitude pulmonary edema. Ann Intern Med 1991;114:569-570. [PubMed: 2001089]

25. West BH, Noureddin N, Mamzhi Y, Low CG, Coluzzi AC, Shih EJ, Gevorgyan Fleming R, Saver JL, Liebeskind DS, Charles A, Tobis JM. Frequency of Patent Foramen Ovale and Migraine in Patients With Cryptogenic Stroke. Stroke 2018;49:1123-1128. [PubMed: 29636424]

26. Mojadidi MK, Bokhoor PI, Gevorgyan R, Noureddin N, MacLellan WC, Wen E, Aysola R, Tobis JM. Sleep Apnea in Patients with and without a Right-to-Left Shunt. J Clin Sleep Med 2015;11:1299-1304. [PubMed: 26094924]

27. Kerut EK, Norfleet WT, Plotnick GD, Giles TD. Patent foramen ovale: a review of associated conditions and the impact of physiological size. Journal of the American College of Cardiology 2001;38:613-623. [PubMed: 11527606]

28. Torti SR, Billinger M, Schwerzmann M, Vogel R, Zbinden R, Windecker S, Seiler C. Risk of decompression illness among 230 divers in relation to the presence and size of patent foramen ovale. European heart journal 2004;25:1014-1020. [PubMed: 15191771]

29. Wagner DR, Fargo JD, Parker D, Tatsugawa K, Young TA. Variables contributing to acute mountain sickness on the summit of Mt Whitney. Wilderness Environ Med 2006;17:221-228. [PubMed: 17219785] 


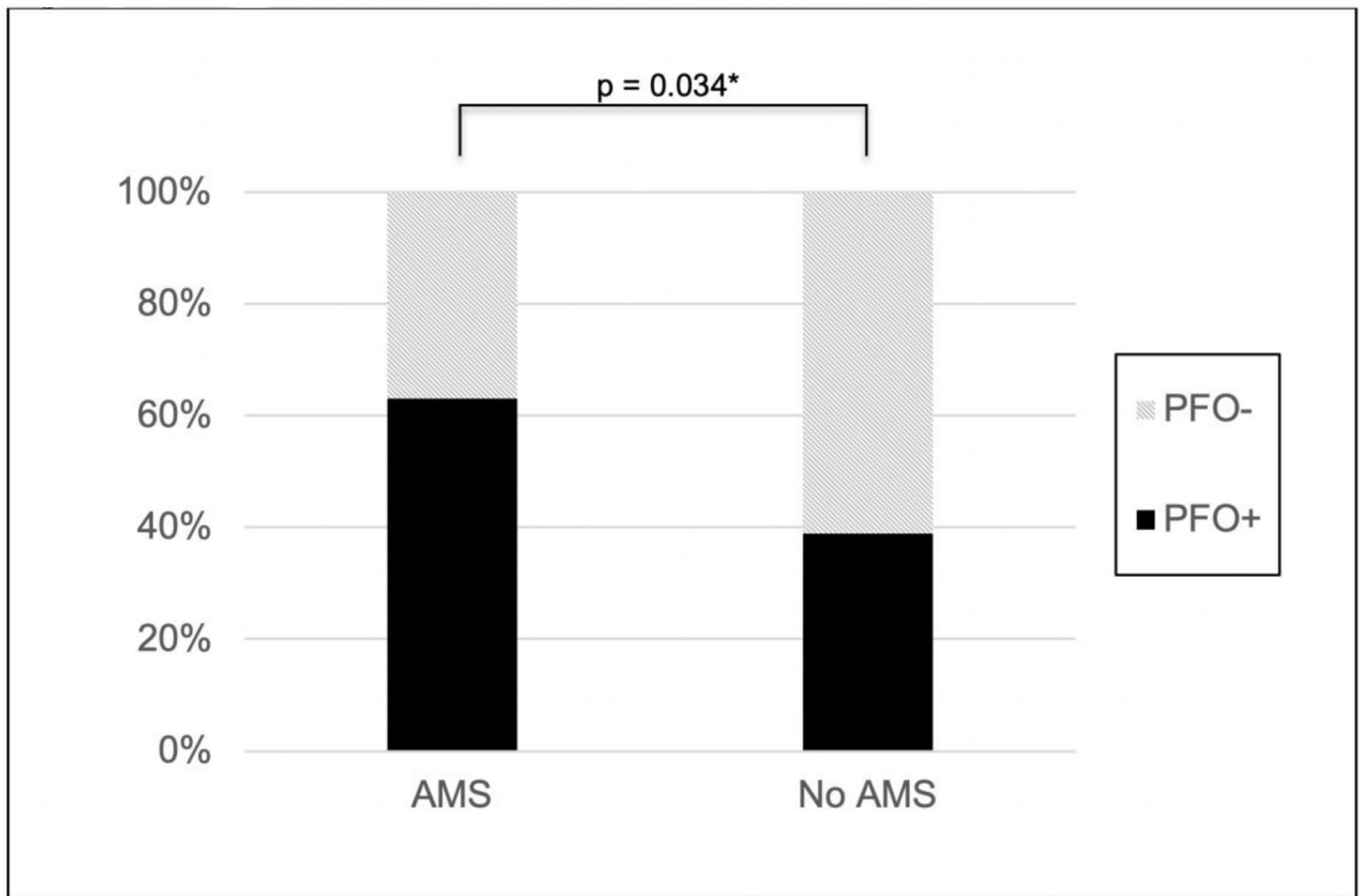

*Comparison via Pearson $\chi 2$, significant at level $\mathrm{p}<0.05$.

Figure 1:

Prevalence of PFO in hikers with and without AMS 


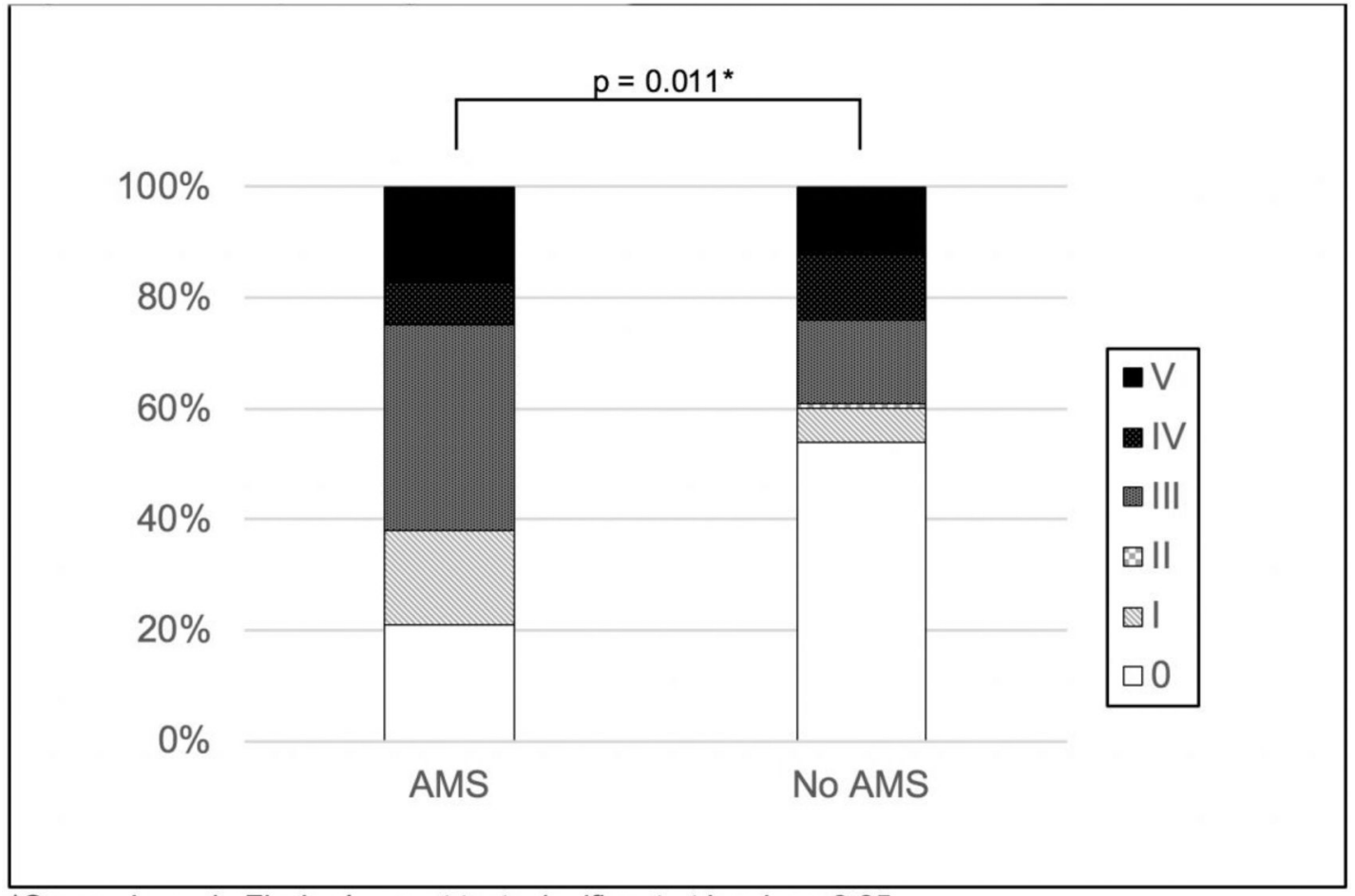

${ }^{*}$ Comparison via Fischer's exact test, significant at level $p<0.05$.

Figure 2:

TCD Spencer grade in hikers with and without AMS 
Table 1:

Baseline characteristics

\begin{tabular}{|c|c|c|c|}
\hline \multirow[b]{2}{*}{ Variable } & \multicolumn{2}{|c|}{ Patent Foramen Ovale } & \multirow[b]{2}{*}{ P-value } \\
\hline & $\begin{array}{c}\text { Yes } \\
(\mathbf{n}=\mathbf{5 9})\end{array}$ & $\begin{array}{c}\text { No } \\
(\mathbf{n}=78)\end{array}$ & \\
\hline Age (years) & $46.5[42.6-50.5]$ & $44.8[41.4-48.2]$ & 0.52 \\
\hline Women & $20(34 \%)$ & $32(41 \%)$ & 0.39 \\
\hline Body mass index $\left(\mathrm{kg} / \mathrm{m}^{2}\right)$ & $23.7[22.7-24.6]$ & $24.1[23.3-24.9]$ & 0.48 \\
\hline Pack weight (lbs) ${ }^{*}$ & $31.8[26.5-37.1]$ & $32.1[28.3-35.9]$ & 0.92 \\
\hline History of smoking (yes) & $3(6 \%)$ & $5(7 \%)$ & 0.75 \\
\hline AMS prophylaxis (yes) & $9(15 \%)$ & $15(19 \%)$ & 0.54 \\
\hline Acclimatization (yes) $)^{\dagger}$ & $26(58 \%)$ & $27(56 \%)$ & 0.88 \\
\hline Saturation at $3,000^{\prime}(\%)$ & $95.8[95.3-96.2]$ & $96.1[95.7-96.5]$ & 0.33 \\
\hline Saturation at $12,500^{\prime}(\%)^{*}$ & $85.3[80.2-90.3]$ & $83.7[77.9-89.5]$ & 0.64 \\
\hline
\end{tabular}

Continuous variables were compared via t-test, median [inter-quartile range]. Categorical variables were compared via Pearson $\chi^{2}$, n (\%).

Based on data for $\mathrm{n}=55$ patients with overnight gear.

Based on data for $\mathrm{n}=93$ patients.

Based on data for $\mathrm{n}=15$ patients. 
Table 2:

\begin{tabular}{|c|c|c|c|c|}
\hline & Multivariate mo & del fo & AMS & \\
\hline & & OR & $95 \% \mathrm{CI}$ & p-value \\
\hline & Age (per year) & 1.00 & $0.96-1.04$ & 0.126 \\
\hline & Gender (female) & 0.61 & $0.18-2.01$ & 0.441 \\
\hline & $\begin{array}{l}\text { AMS prophylaxis } \\
\text { (yes) }\end{array}$ & 1.23 & $0.28-5.35$ & 0.780 \\
\hline & $\begin{array}{l}\text { Acclimatization } \\
\text { (yes) }\end{array}$ & 0.51 & $0.16-1.68$ & 0.270 \\
\hline & PFO (positive) & 4.15 & $1.14-15.05$ & $0.030 *$ \\
\hline
\end{tabular}

Significant at level $\mathrm{p}<0.05$ 